\title{
DATA MINING PENILAIAN KINERJA KARYAWAN UPI CONVENTION GROUP MENGGUNAKAN BAYESIAN CLASSIFIER
}

\author{
Eka Praja Wiyata Mandala'), Muhammad Ridwan ${ }^{2)}$, dan Dewi Eka Putri ${ }^{3)}$ \\ ${ }^{1,3}$ Teknik Informatika, Fakultas Ilmu Komputer, Universitas Putra Indonesia YPTK Padang \\ ${ }^{2}$ Manajemen, Fakultas Ekonomi dan Bisnis, Universitas Putra Indonesia YPTK Padang \\ ${ }_{1,2,3}$ Jl. Raya Lubuk Begalung, Padang, Sumatera Barat, 25221 \\ E-mail : ekaprajawm@upiyptk.ac.id ${ }^{1)}$,muhammad_ridwan@upiyptk.ac.id ${ }^{2)}$,dewieka@upiyptk.ac.id ${ }^{3)}$
}

\begin{abstract}
ABSTRAK
Kinerja merupakan tingkat berhasilnya seorang karyawan dalam periode tertentu ketika melaksanakan pekerjaannya berupa standar dari hasil kerja dan target yang sudah dicapai. Kinerja biasa juga disebut dengan prestasi kerja yang merupakan gabungan dari kemampuan dari seorang karyawan, usaha yang dilakukannya dan kesempatan yang bisa dinilai dari semua hasil kerjanya. Penilaian kinerja karyawan harus dilakukan pada semua bidang usaha yang melibatkan karyawan didalamnya, termasuk UPI Convention Group sebagai pengelola gedung pertemuan dan penyedia fasilitas untuk menunjang semua kegiatan yang dilakukan di gedung tersebut. UPI Convention Group memiliki karyawan tetap yang ditempatkan pada dua gedung yang dikelola yaitu UPI Exhibition Hall dan UPI Convention Center. Padatnya kegiatan yang dilakukan pada kedua gedung tersebut, diantaranya adalah acara pernikahan, seminar, pertemuan dan kegiatan lainnya membuat pihak manajemen UPI Convention Group mempunyai masalah dengan kinerja karyawan mereka yang dirasakan tidak stabil, kadang kinerja mereka bagus, kadang kurang bagus. Karena masalah ini, maka diperlukan sebuah aplikasi pendukung untuk melakukan penilaian kinerja karyawan di UPI Convention Group, dimana aplikasi ini dibuat menggunakan pendekatan data mining dengan metode bayesian classifier untuk menentukan nilai probabilitas dari masingmasing kriteria penilaian. Hasilnya sangat membantu manajemen UPI Convention Group dalam proses penilaian kinerja karyawan berdasarakan kriteria-kriteria yang sudah ditentukan.
\end{abstract}

Kata Kunci: data mining, bayesian classifier, kriteria, kinerja, karyawan,

\section{PENDAHULUAN}

Sebuah perusahaan atau apapun bidang usaha pasti memiliki karyawan sebagai penggerak perusahaan mereka. Karyawan pada perusahaan harus dikelola dengan baik agar perusahaan tersebut bisa berjalan dengan baik dan bisa mencapai tujuan yang telah ditetapkan oleh perusahaan tersebut.

Karyawan itu sendiri merupakan orang-orang yang mempunyai pekerjaan sebagai pekerja dalam perusahaan yang mengerjakan kegiatan operasional dengan menerima balas jasa berupa uang (Palupi, Lailiyah and Sihotang, 2018).

Salah satu contoh bidang usaha yang memiliki karyawan adalah UPI Convention Group yang memiliki karyawan tetap untuk mengerjakan pekerjaan rutin saat gedung disewa untuk berbagai kegiatan, misalnya acara pernikahan, pertemuan, seminar, pelatihan, bursa kerja dan sebagainya. Padatnya kegiatan yang dilakukan, membuat pihak manajemen harus melakukan penilaian terhadap kinerja karyawan mereka.

Penilaian kinerja tidak bisa dilakukan secara langsung dari hasil kerja karyawan tersebut saja, tapi juga harus dipertimbangkan kriteria-kriteria penilaian kinerja terhadap karyawan tersebut, sehingga hasil yang akan diperoleh oleh pihak manajemen juga semakin akurat. Hal ini akan berhubungan dengan tindak lanjut yang akan diambil terhadap karyawan yang dinilai tersbut, apakah karyawan tersebut tetap bisa digunakan jasanya, atau harus diputus hubungan kerjanya dengan pihak manajemen UPI Convention Group.

Kinerja dari seorang karyawan bisa bernilai baik atau bernilai buruk, jika ada proses penilaian dari tingkat keterlibatan karyawan tersebut terhadap pekerjaan. Penilaian dari kinerja seorang karyawan adalah evaluasi dari berhasil atau tidaknya karyawan tersbut dalam melaksanakan tugasnya (Sari, Rinawati, Arvianto and Mujur, 2014).

Penelitian ini akan menggunakan data yang diperoleh langsung dari manajer operasional UPI Convention Group berupa data karyawan yang dilengkapi dengan kriteria dalam penilaian kinerja karyawan yang sudah diterapkan. Sebagian besar data yang diperoleh merupakan hasil wawancara yang dilakukan langsung dengan manajer operasional dan melakukan pengamatan secara langsung bagaimana karyawan tersebut bekerja saat ada acara yang dilakukan di gedung UPI Convention Center atau UPI Exhibition Hall. 
Berdasarkan penelitian yang sudah dilakukan sebelumnya tentang penilaian kinerja karyawan menghasilkan sebuah sistem pendukung keputusan yang menggunakan pendekatan data mining dengan Algoritma C4.5 pada PT. Mulya Spindo Mills. Penelitian tersebut menggunakan pendekatan data mining, tetapi memakai metode yang berbeda dengan metode pada penelitian ini yaitu Algoritma C4.5 (Saefudin and Lestari, 2015).

Penelitian tentang kinerja karyawan juga pernah dilakukan sebelumnya yaitu di UPI Convention Center Padang tentang bagaimana pengaruh antara kompensasi yang diberikan, disiplin kerja yang diterapkan dan komitmen dari karyawan untuk menentukan kinerja dari karyawan Penelitian tersebut menjelaskan penilaian kinerja karyawan yang dilihat dari sisi manajemen (Ridwan, 2017).

Penelitian tentang penilaian prestasi kerja dari karyawan juga sudah pernah dilakukan di PTPN III Pematangsiantar dengan memakai metode Simple Additive Weighting. Penelitian tersebut menghasilkan sebuah sistem untuk mendukung keputusan dalam penilaian prestasi kerja karyawan (Windarto, 2017).

Dari beberapa penelitian yang sudah dilakukan sebelumnya, penilaian kinerja karyawan lebih banyak dilakukan dengan pendekatan sistem pendukung keputusan. Ada pun penelitian yang menggunakan pendekatan data mining, tetapi tidak menggunakan metode yang sama pada penelitian ini.

Jadi, pemecahan yang dikemukakan pada penelitian ini yaitu pendekatan data mining menggunakan metode bayesian classifier yaitu proses klasifikasi statistik yang digunakan untuk melakukan prediksi keanggotaan dari sebuah class (Mandala, 2015). Bayesian Classifier adalah metode untuk melakukan klasifikasi probabilitas sederhana yang didasarkan pada pendekatan Teorema Bayes (Pauziah, 2017).

Bayes adalah klasifikasi probabilistik sederhana untuk menghitung serangkaian kemungkinan dengan menjumlahkan frekuensi dan kombinasi nilai dari yang diberikan oleh dataset (Mulyati and Setiani, 2018). Metode Bayes berbasis nilai kepastian atau tingkat keyakinan (Ramadhoni, Mandala and Afdhal, 2019).

Hasil penelitian yang dilakukan berupa aplikasi berbasis web dengan pendekatan data mining yang dapat menunjang keputusan manajemen UPI Convention Group dalam penilaian kinerja karyawan. Penelitian ini menggunakan bahasa PHP yang merupakan singkatan dari PHP : Hypertext Preprocessor yaitu bahasa skrip yang disisipkan dalam HTML yang dipakai untuk menghasilkan web dinamis dan ditunjang juga dengan basis data server yaitu MySQL yang mampu menangani data yang komplek dan data yang cukup besar (Mandala, 2015).

\section{RUANG LINGKUP}

Adapun ruang lingkup dari penelitian yang dilakukan mencakup :

1. Cakupan dari permasalahan.

Banyaknya karyawan tetap untuk operasional semua kegiatan yang dilakukan, membuat manajemen $U P I$
Convention Group harus bisa mempersiapkan karyawan mereka untuk bisa totalitas pada semua kegiatan yang padat tersebut. Sehingga penilaian kinerja dari masing-masing karyawan harus dilakukan agar bisa menjaga profesionalitas dari masing-masing karyawan.

2. Batasan-batasan dalam penelitian.

Penelitian ini dilakukan untuk melakukan penilaian terhadap kinerja dari masing-masing karyawan dengan menggunakan data karyawan dan kriteria penilaian yang diberikan langsung oleh manajer operasional UPI Convention Group melalui wawancara yang dilakukan. Beberapa kriteria yang diperoleh untuk melakukan penilaian kinerja karyawan adalah : Kepribadian, Taat aturan, Kedisiplinan, Tanggung jawab, Ketelitian, Produktivitas dan Kerapian.

3. Rencana hasil penelitian yang diperoleh.

Penelitian ini akan menghasilkan sebuah aplikasi data mining yang bisa melakukan penilaian terhadap kinerja yang sudah dilakukan oleh masing-masing karyawan dari UPI Convention Group berdasarkan kriteria yang sudah ditetapkan sebelumnya. Aplikasi yang dihasilkan berbasis media web yang bisa digunakan secara lokal maupun online.

\section{BAHAN DAN METODE}

Beberapa landasan teoritis dan metodologi yang digunakan pada penelitian ini, diantaranya adalah :

\subsection{Data Mining}

Data mining dapat diartikan sebagai analisis dan pengamatan data yang besar untuk mendapatkan hubungan dan meringkas data agar dapat dimengerti dan dapat digunakan pemilik data (Han and Kamber, 2011).

Pada pengertian lain, data mining melakukan proses ekstraksi agar memperoleh informasi secara implisit dan tidak diketahui sebelumnya dari sebuah data (Witten, Eibe and Hall, 2011).

Data mining melakukan ekstraksi terhadap data untuk mendapatkan informasi penting bersifat implisit dan tidak di ketahui dari data (Putri, 2015).

Jadi data mining bisa dikatakan sebagai cara untuk menjelaskan masa yang telah lalu dan memprediksi masa depan melalui analisis data. Data mining merupakan kombinasi dari pembelajaran mesin, statistik, teknologi database dan kecerdasan buatan (Mandala, 2015).

\subsection{Bayesian Classifier}

Bayesian Classifier mempunyai tingkat akurasi dan nilai kecepatan yang tinggi pada saat diimplementasi menggunakan basis data yang sangat besar (Mandala, 2015).

Bentuk umum dari Teorema Bayes dapat dilihat pada Rumus (1) dibawah ini (Mandala, 2015) :

$$
\mathrm{P}(\mathrm{H} \mid \mathrm{E})=\frac{(\mathrm{P}(\mathrm{E} \mid \mathrm{H}) \times \mathrm{P}(\mathrm{H}))}{\mathrm{P}(\mathrm{E})}
$$

Dimana $X$ adalah data yang belum diketahui, $H$ adalah hipotesis E, $P(H \mid E)$ adalah probabilitas hipotesis $\mathrm{H}$ berdasarkan E, $P(H)$ adalah Probabilitas hipotesis $\mathrm{H}$, $P(E \mid H)$ adalah probabilitas $\mathrm{E}$ berdasarkan hipotesis $\mathrm{H}$, dan $P(E)$ adalah probabilitas E. 


\subsection{Metodologi Penelitian}

Kerangka penelitian yang dipakai pada penelitian ini terlihat pada Gambar 1 :

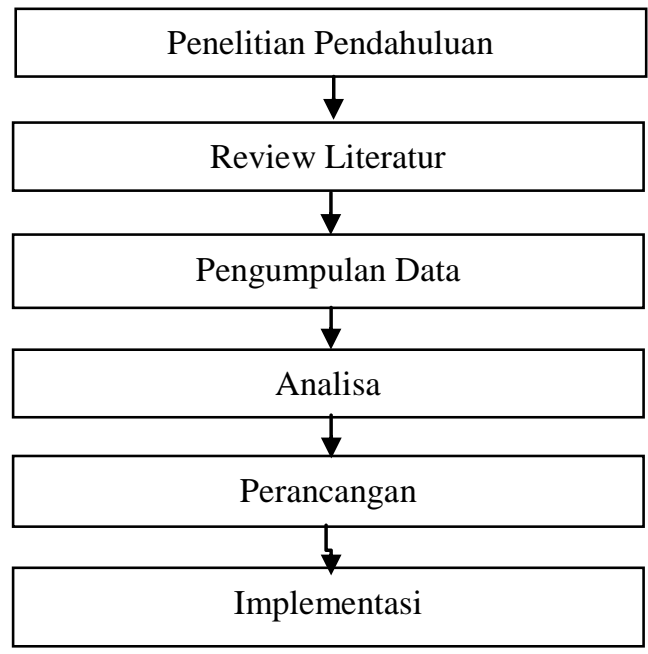

Gambar 1. Kerangka Penelitian

Dari kerangka penelitian pada Gambar 1, dapat dijelaskan masing-masing langkah kerja sebagai berikut :

1. Penelitian Pendahuluan

Langkah awal dari penelitian yang dilakukan yaitu melakukan observasi secara langsung untuk mempelajari masalah yang terjadi tentang penilaian kinerja karyawan di UPI Convention Group.

2. Review Literatur

Mempelajari semua literatur yang berhubungan dengan penelitian yang dilakukan berupa penelitian yang sudah dilakukan sebelumnya mengenai penilaian kinerja karyawan.

3. Pengumpulan Data

Melakukan wawancara langsung dengan manajer operasional UPI Convention Group yaitu Bapak Hendra Arsona untuk memperoleh data karyawan dan kriteria penilaian dari kinerja karyawan yang sudah ditetapkan oleh manajemen UPI Covention Group.

4. Analisa

Melakukan analisa terhadap data yang diperoleh dengan memakai metode bayesian classifier dengan menggunakan kriteria yang sudah diperoleh sebelumnya.

5. Perancangan

Melakukan perancangan sistem dengan alat bantu untuk merancang sistem yaitu Unified Modeling Language. Menghasilkan use case diagram yang menunjukkan interaksi antara pengguna dengan aplikasi data mining.

6. Implementasi

Merubah hasil perancangan ke dalam bentuk aplikasi dengan menggunakan bahasa web yaitu PHP dan didukung dengan basis data MySQL server.

\section{PEMBAHASAN}

Pada pembahasan akan dijelaskan tentang analisa, perancangan dan implementasi.

\subsection{Analisa}

Dalam penilaian kinerja karyawan di UPI Convention Group, terdapat beberapa kriteria yang diperoleh dari hasil wawancara dengan Bapak Hendra Arsona sebagai manajer operasional.

Kriteria untuk penilaian kinerja seorang karyawan dapat dilihat pada Tabel 1 :

\section{Tabel 1. Kriteria Penilaian Kinerja Karyawan}

\begin{tabular}{|c|c|l|}
\hline No & $\begin{array}{c}\text { Kode } \\
\text { Kriteria }\end{array}$ & \multicolumn{1}{c|}{ Kriteria } \\
\hline 1 & A & Kepribadian \\
\hline 2 & B & Taat Aturan \\
\hline 3 & C & Kedisiplinan \\
\hline 4 & D & Tanggung Jawab \\
\hline 5 & E & Ketelitian \\
\hline 6 & F & Produktivitas \\
\hline 7 & G & Kerapian \\
\hline
\end{tabular}

Setelah kriteria ditentukan, maka harus diberikan klasifikasi dari masing-masing kriteria. Mulai dari kriteria Kepribadian memiliki klasifikasi seperti Tabel 2.

Tabel 2. Klasifikasi Kriteria Kepribadian

\begin{tabular}{|c|c|c|c|}
\hline No & Kriteria Kepribadian & $\begin{array}{c}\text { Klasifi } \\
\text { kasi }\end{array}$ & Kode \\
\hline 1 & $\begin{array}{l}\text { Hormat dan patuh kepada } \\
\text { pimpinan dan santun pada } \\
\text { sesama karyawan dan ramah } \\
\text { terhadap tamu pada saat ada } \\
\text { kegiatan }\end{array}$ & $\begin{array}{l}\text { Sangat } \\
\text { sopan }\end{array}$ & A1 \\
\hline 2 & $\begin{array}{l}\text { Sopan pada pimpinan dan sesama } \\
\text { karyawan tapi agak kurang } \\
\text { ramah dengan tamu pada saat ada } \\
\text { kegiatan }\end{array}$ & Sopan & A2 \\
\hline 3 & $\begin{array}{l}\text { Hanya takut pada pimpinan dan } \\
\text { agak kurang peduli dengan } \\
\text { sesama karyawan dan seperti } \\
\text { tidak mau tahu terhadap tamu } \\
\text { pada saat ada kegiatan }\end{array}$ & $\begin{array}{c}\text { Kurang } \\
\text { Sopan }\end{array}$ & A3 \\
\hline
\end{tabular}

Kriteria Taat Aturan memiliki klasifikasi seperti Tabel 3.

Tabel 3. Klasifikasi Kriteria Taat Aturan

\begin{tabular}{|c|l|c|c|}
\hline No & \multicolumn{1}{|c|}{ Kriteria Taat Aturan } & $\begin{array}{c}\text { Klasifi } \\
\text { kasi }\end{array}$ & Kode \\
\hline 1 & $\begin{array}{l}\text { Mematuhi semua peraturan } \\
\text { yang sudah ditetapkan pihak } \\
\text { manajemen dan bekerja sesuai } \\
\text { dengan peraturan yang ada }\end{array}$ & Patuh & B1 \\
\hline 2 & $\begin{array}{l}\text { Bekerja sesuai dengan } \\
\text { ketentuan yang berlaku tapi } \\
\text { kadang suka mengabaikan } \\
\text { perintah dari pimpinan. }\end{array}$ & $\begin{array}{c}\text { Kurang } \\
\text { Patuh }\end{array}$ & B2 \\
\hline 3 & $\begin{array}{l}\text { Suka bekerja sesuai dengan } \\
\text { kemauan sendiri dan tidak } \\
\text { sesuai dengan peraturan yang } \\
\text { ada }\end{array}$ & Tidak \\
Patuh & B3 \\
\hline
\end{tabular}

Kriteria Kedisiplinan memiliki klasifikasi seperti Tabel 4. 
Tabel 4. Klasifikasi Kriteria Kedisiplinan

\begin{tabular}{|c|l|c|c|}
\hline No & \multicolumn{1}{|c|}{ Kriteria Kedisiplinan } & $\begin{array}{c}\text { Klasifik } \\
\text { asi }\end{array}$ & Kode \\
\hline 1 & $\begin{array}{l}\text { Selalu datang lebih awal dari } \\
\text { jadwal mulai bekerja, bekerja } \\
\text { sesuai dengan lama jam kerja } \\
\text { dan selalu hadir saat diadakan } \\
\text { briefing internal }\end{array}$ & $\begin{array}{c}\text { Sangat } \\
\text { Disiplin }\end{array}$ & $\mathrm{C} 1$ \\
\hline 2 & $\begin{array}{l}\text { Datang pas-pas waktu, pulang } \\
\text { juga pas-pas waktu, briefing } \\
\text { kadang-kadang ikut }\end{array}$ & Disiplin & $\mathrm{C} 2$ \\
\hline 3 & $\begin{array}{l}\text { Sering terlambat datang, pulang } \\
\text { lebih awal dan briefing sering } \\
\text { tidak ikut. }\end{array}$ & $\begin{array}{c}\text { Kurang } \\
\text { Disiplin }\end{array}$ & $\mathrm{C} 3$ \\
\hline
\end{tabular}

Kriteria Tanggung Jawab memiliki klasifikasi seperti Tabel 5.

Tabel 5. Klasifikasi Kriteria Tanggung Jawab

\begin{tabular}{|c|l|c|c|}
\hline No & Kriteria Tanggung Jawab & $\begin{array}{c}\text { Klasifika } \\
\text { si }\end{array}$ & Kode \\
\hline 1 & $\begin{array}{l}\text { Berusaha untuk melakukan } \\
\text { dan menyelesaikan pekerjaan } \\
\text { yang sudah diberikan sampai } \\
\text { selesai }\end{array}$ & $\begin{array}{c}\text { Sangat } \\
\text { Besar }\end{array}$ & D1 \\
\hline 2 & $\begin{array}{l}\text { Bisa mengerjakan pekerjaan } \\
\text { yang diberikan walaupun tidak } \\
\text { selesai dengan sempurna }\end{array}$ & Lumayan & D2 \\
\hline 3 & $\begin{array}{l}\text { Pekerjaan yang diberikan tidak } \\
\text { terlihat hasilnya walaupun } \\
\text { sedikit }\end{array}$ & Kurang & D3 \\
\hline
\end{tabular}
6. :

Kriteria Ketelitian memiliki klasifikasi seperti Tabel

Tabel 6. Klasifikasi Kriteria Ketelitian

\begin{tabular}{|c|l|c|c|}
\hline No & \multicolumn{1}{|c|}{ Kriteria Ketelitian } & $\begin{array}{c}\text { Klasifi } \\
\text { kasi }\end{array}$ & Kode \\
\hline 1 & $\begin{array}{l}\text { Selalu berusaha menyelesaikan } \\
\text { pekerjaan dengan sempurna, } \\
\text { tanpa ada cacat sedikitpun }\end{array}$ & $\begin{array}{c}\text { Sangat } \\
\text { Teliti }\end{array}$ & E1 \\
\hline 2 & $\begin{array}{l}\text { Pekerjaan selesai dengan baik } \\
\text { tapi pada saat akhir masih ada } \\
\text { beberapa yang kurang }\end{array}$ & Teliti & E2 \\
\hline 3 & $\begin{array}{l}\text { Selalu mengabaikan hal-hal } \\
\text { yang penting dari pekerjaan } \\
\text { yang dilakukan }\end{array}$ & $\begin{array}{c}\text { Kurang } \\
\text { Teliti }\end{array}$ & E3 \\
\hline
\end{tabular}

Kriteria Produktivitas memiliki klasifikasi seperti Tabel 7.

Tabel 7. Klasifikasi Kriteria Produktivitas

\begin{tabular}{|c|l|c|c|}
\hline No & \multicolumn{1}{|c|}{ Kriteria Produktivitas } & $\begin{array}{c}\text { Klasifik } \\
\text { asi }\end{array}$ & Kode \\
\hline 1 & $\begin{array}{l}\text { Bisa mengerjakan dan } \\
\text { menyelesaikan pekerjaan yang } \\
\text { diberikan lebih dari satu }\end{array}$ & Banyak & F1 \\
\hline 2 & $\begin{array}{l}\text { Hanya bisa mengerjakan dan } \\
\text { menyelesaikan satu pekerjaan saja }\end{array}$ & Sedikit & F2 \\
\hline 3 & $\begin{array}{l}\text { Bisa melakukan pekerjaan, tapi } \\
\text { tidak satupun pekerjaan yang } \\
\text { selesai }\end{array}$ & $\begin{array}{c}\text { Tidak Ada } \\
\text { Ada }\end{array}$ & F3 \\
\hline
\end{tabular}
8.

Kriteria Kerapian memiliki klasifikasi seperti Tabel

Tabel 8. Klasifikasi Kriteria Kerapian

\begin{tabular}{|c|l|c|c|}
\hline No & \multicolumn{1}{|c|}{ Kriteria Kerapian } & $\begin{array}{c}\text { Klasifik } \\
\text { asi }\end{array}$ & Kode \\
\hline 1 & $\begin{array}{l}\text { Selalu berpakai rapi baik saat } \\
\text { ada kegiatan maupun tidak ada } \\
\text { kegiatan yang dilakukan }\end{array}$ & $\begin{array}{c}\text { Sangat } \\
\text { Rapi }\end{array}$ & G1 \\
\hline 2 & $\begin{array}{l}\text { Hanya berpakaian rapi saat ada } \\
\text { kegiatan saja }\end{array}$ & Rapi & G2 \\
\hline 3 & $\begin{array}{l}\text { Pada saat ada kegiatan pun } \\
\text { terlihat pakaian kurang rapi. }\end{array}$ & $\begin{array}{c}\text { Kurang } \\
\text { Rapi }\end{array}$ & G3 \\
\hline
\end{tabular}

Target yang akan dicapai sebagai keputusan yaitu Kinerja Karyawan dengan tiga atribut seperti pada Tabel 9.

Tabel 9. Klasifikasi Target Kinerja Karyawan

\begin{tabular}{|c|c|c|}
\hline No & Klasifikasi Kinerja Karyawan & Kode \\
\hline 1 & Sangat Bagus & $\mathrm{Z} 1$ \\
\hline 2 & Bagus & $\mathrm{Z} 2$ \\
\hline 3 & Kurang Bagus & $\mathrm{Z} 3$ \\
\hline
\end{tabular}

Data karyawan yang diperoleh dari hasil wawancara dengan manajer operasional UPI Convention Group, diperoleh data karyawan untuk training sebanyak 10 data karyawan. Data training yang digunakan bisa dilihat pada Tabel 10.

Tabel 10. Sample Data Training

\begin{tabular}{|c|c|c|c|c|c|c|c|c|}
\hline \multirow{2}{*}{ No } & \multicolumn{7}{|c|}{ Kriteria } & $\begin{array}{c}\text { Tar } \\
\text { get }\end{array}$ \\
\cline { 2 - 10 } & A & B & C & D & E & F & G & Z \\
\hline 1 & A1 & B1 & C1 & D1 & E1 & F1 & G1 & Z1 \\
\hline 2 & A2 & B3 & C2 & D2 & E3 & F3 & G3 & Z3 \\
\hline 3 & A2 & B1 & C2 & D1 & E1 & F1 & G2 & Z1 \\
\hline 4 & A2 & B1 & C2 & D3 & E2 & F1 & G3 & Z2 \\
\hline 5 & A2 & B2 & C2 & D2 & E2 & F2 & G2 & Z2 \\
\hline 6 & A3 & B3 & C3 & D2 & E3 & F3 & G2 & Z3 \\
\hline 7 & A1 & B1 & C1 & D1 & E1 & F2 & G2 & Z1 \\
\hline 8 & A3 & B3 & C3 & D3 & E3 & F3 & G3 & Z3 \\
\hline 9 & A1 & B2 & C3 & D1 & E2 & F3 & G2 & Z2 \\
\hline 10 & A1 & B1 & C3 & D3 & E2 & F2 & G1 & Z2 \\
\hline
\end{tabular}

Jika ada karyawan ke-11 yang akan dinilai kinerjanya, maka karyawan ke-11 dijadikan sebagai data testing. Misalnya karyawan ke-11 memiliki kriteria sebagai berikut :
1. Kepribadian
$=$ Sopan
[A2]
2. Taat Aturan
$=$ Kurang Patuh [B2]
3. Kedisiplinan
$=$ Disiplin
4. Tanggung Jawab $=$ Sangat Besar
5. Ketelitian
$=$ Teliti
6. Produktivitas
$=$ Sedikit
7. Kerapian
$=$ Sangat Rapi

Jika kriteria karyawan seperti keadaan diatas, maka untuk mendapatkan keputusan tentang kinerja karyawan, dapat digunakan Bayesian Classifier dengan perhitungan sebagai berikut : 
$\mathrm{P}($ Sangat Bagus [Z1] $\quad=3 / 10=0.3$
$\mathrm{P}($ Bagus [Z2] $) \quad=4 / 10=0.4$
$\mathrm{P}($ Kurang Bagus [Z3]) $=3 / 10=0.3$
$\mathrm{P}($ Sopan [A2] $\mid$ Sangat Bagus $[\mathrm{Z} 1])=2 / 3=0.667$
$\mathrm{P}($ Sopan [A2] $\mid$ Bagus $[\mathrm{Z} 2]) \quad=2 / 4=0.5$
$\mathrm{P}($ Sopan [A2] $\mid$ Kurang Bagus $[\mathrm{Z} 3])=1 / 3=0.333$

$\mathrm{P}($ Kurang Patuh [B2] | Sangat Bagus [Z1]) $=0 / 3=0$

$\mathrm{P}($ Kurang Patuh [B2] $\mid$ Bagus [Z2] $)=2 / 4=0.5$

$\mathrm{P}($ Kurang Patuh [B2] $\mid$ Kurang Bagus [Z3]) $=0 / 3=0$

$\mathrm{P}($ Disiplin [C2] $\mid$ Sangat Bagus $[Z 1])=1 / 3=0.333$

$\mathrm{P}($ Disiplin [C2] $\mid$ Bagus [Z2]) $=2 / 4=0.5$

$\mathrm{P}($ Disiplin [C2] $\mid$ Kurang Bagus [Z3] $)=1 / 3=0.333$

$\mathrm{P}($ Sangat Besar $[\mathrm{D} 1] \mid$ Sangat Bagus $[\mathrm{Z1}])=3 / 3=1$

$\mathrm{P}($ Sangat Besar [D1] $\mid$ Bagus $[\mathrm{Z2}]) \quad=1 / 4=0.25$

$\mathrm{P}($ Sangat Besar $[\mathrm{D} 1] \mid$ Kurang Bagus $[\mathrm{Z} 3])=0 / 3=0$

$\mathrm{P}($ Teliti [E2] $\mid$ Sangat Bagus [Z1]) $=0 / 3=0$

$\mathrm{P}($ Teliti [E2] $\mid$ Bagus [Z2]) $\quad=4 / 4=1$

$\mathrm{P}($ Teliti $[\mathrm{E} 2] \mid$ Kurang Bagus $[\mathrm{Z3}])=0 / 3=0$

$\mathrm{P}($ Sedikit $[\mathrm{F} 2] \mid$ Sangat Bagus $[\mathrm{Z} 1])=1 / 3=0.333$

$\mathrm{P}($ Sedikit [F2] $\mid$ Bagus [Z2]) $=2 / 4=0.5$

$\mathrm{P}($ Sedikit $[\mathrm{F} 2] \mid$ Kurang Bagus $[\mathrm{Z} 3])=0 / 3=0$

$\mathrm{P}($ Sangat Rapi [G1] | Sangat Bagus $[\mathrm{Z1}])=1 / 3=0.333$

$\mathrm{P}($ Sangat Rapi [G1] $\mid$ Bagus [Z2]) $\quad=1 / 4=0.25$

$\mathrm{P}($ Sangat Rapi $[\mathrm{G} 1] \mid$ Kurang Bagus $[\mathrm{Z} 3])=0 / 3=0$

$\mathrm{P}(\mathrm{X} \mid$ Sangat Bagus [Z1])

$=0.667 \times 0 \times 0.333 \times 1 \times 0 \times 0.333 \times 0.333$

$=0.0000$

$\mathrm{P}(\mathrm{X} \mid$ Bagus [Z2])

$=0.5 \times 0.5 \times 0.5 \times 0.25 \times 1 \times 0.5 \times 0.25$

$=0.0039$

$\mathrm{P}(\mathrm{X} \mid$ Kurang Bagus [Z3])

$=0.333 \times 0 \times 0.333 \times 0 \times 0 \times 0 \times 0$

$=0.0000$

$\mathrm{P}(\mathrm{X} \mid$ Sangat Bagus [Z1]) x P(Sangat Bagus [Z1])

$=0.0000 \times 0.3$

$=0.000$

$\mathrm{P}(\mathrm{X} \mid$ Bagus [Z2]) x $\mathrm{P}($ Bagus [Z2])

$=0.0039 \times 0.4$

$=0.0016$

$\mathrm{P}(\mathrm{X} \mid$ Kurang Bagus [Z3]) x P(Kurang Bagus [Z3])

$=0.0000 \times 0.3$

$=0.000$

Jadi, dari hasil perhitungan diatas bisa dilihat bahwa nilai probabilitas Kinerja Bagus lebih tinggi dari pada nilai Kinerja Sangat Bagus dan Kinerja Kurang Bagus yaitu 0.0016 , maka dapat disimpulkan bahwa karyawan dengan kriteria :
1. Kepribadian = Sopan [A2]

2. Taat Aturan = Kurang Patuh [B2]

3. Kedisiplinan = Disiplin [C2]

4. Tanggung Jawab = Sangat Besar [D1]

5. Ketelitian = Teliti [E2]

6. Produktivitas = Sedikit [F2]

7. Kerapian = Sangat Rapi [G1]

maka karyawan tersebut memiliki kinerja bagus

\subsection{Perancangan dan Implementasi Sistem}

Setelah proses analisa selesai, maka dilanjutkan dengan proses perancangan aplikasi data mining penilaian kinerja karyawan UPI Convention Group.

Perancangan sistem dari proses analisa awal terhadap sistem yang akan dibuat. Hasil analisa akan bisa lebih mudah untuk menggambarkan bagaimana sistem yang akan dibuat secara umum. Setelah dapat gambaran dari sistem, maka akan dimulai proses desain sistem dengan menghasilkan antar muka dari masing-masing halaman aplikasi. Kemudian dilakukan proses seleksi sistem untuk mendapatkan sistem yang sesuai dengan kebutuhan yang diinginkan. Terakhir, sistem akan diimplementasikan ke dalam bahasa pemrograman yaitu PHP agar bisa digunakan oleh manajemen UPI Convention Group. Proses perancangan sistem terlihat pada Gambar 2 :

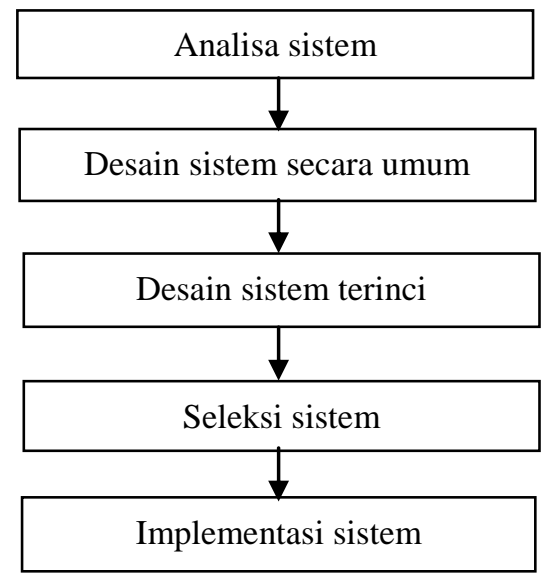

Gambar 2. Proses Perancangan Sistem

Implementasi sistem berupa hasil antar muka dari masing-masing halaman dari aplikasi data mining.

1. Halaman Login

Halaman login untuk masuk ke aplikasi data mining terlihat pada Gambar 3 : 


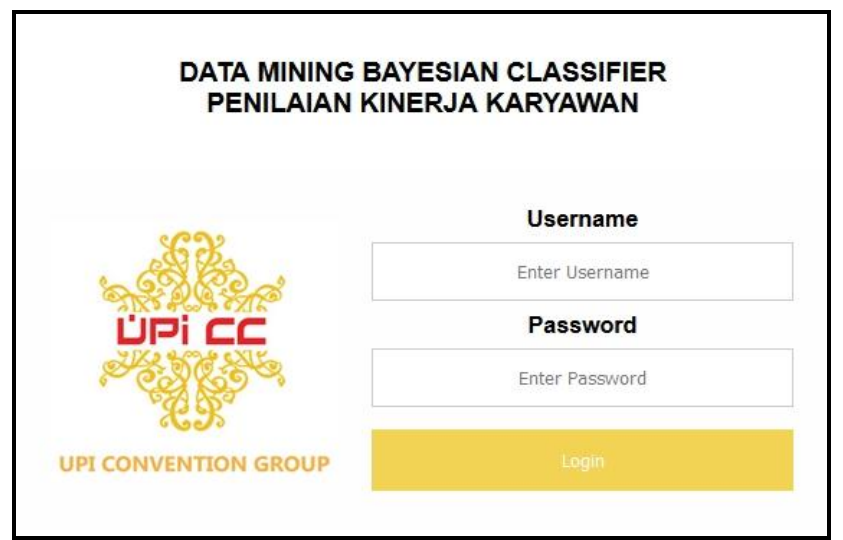

Gambar 3. Halaman Login Manajer

Halaman login digunakan untuk membatasi akses pengguna aplikasi data mining. Hanya manajer operasional yang berhak menggunakan aplikasi data mining

2. Halaman Tambah Data Training

Halaman tambah data training digunakan untuk memasukkan sample data training ditunjukkan pada Gambar 4.

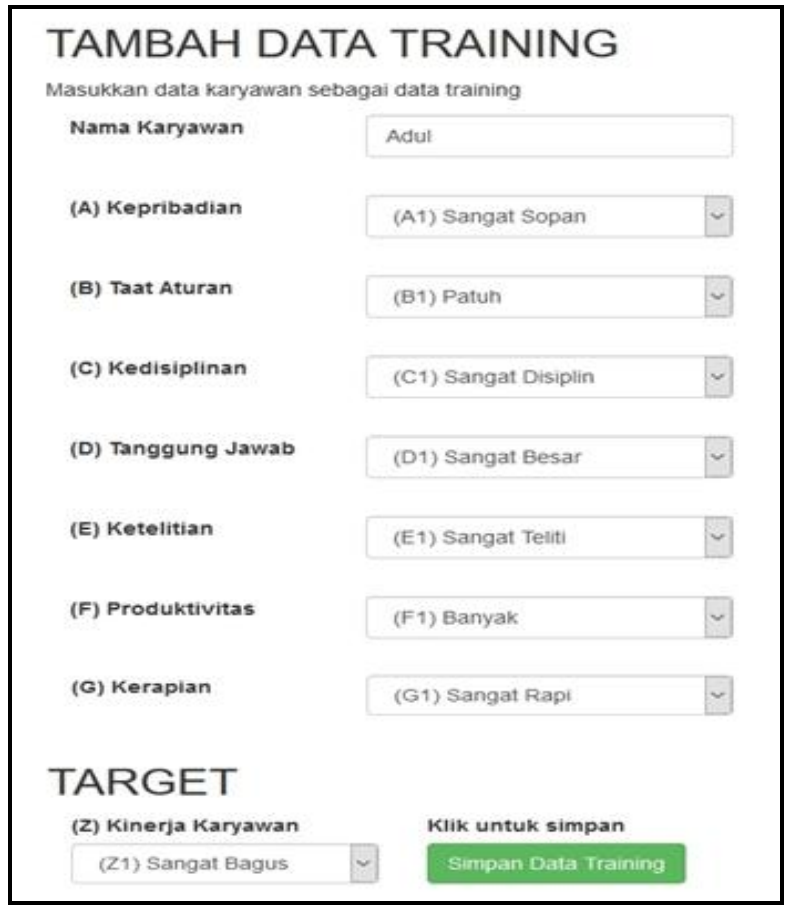

Gambar 4. Halaman Tambah Data Training

Halaman tambah data training digunakan untuk menyimpan sampel data yang akan digunakan sebagai data training untuk digunakan mencari nilai probabilitas masing-masing kriteria.

\section{Halaman Proses Bayesian Classifier}

Halaman proses Bayesian Classifier yang menjadi inti dari aplikasi data mining, karena disini proses bayesian classifier akan dimulai. Berikut antar muka halamannya ditunjukkan pada Gambar 5.

\begin{tabular}{|c|c|c|}
\hline \multicolumn{3}{|c|}{ Masukkan data karyawan baru untuk mendapatkan kinerja karyawan } \\
\hline Nama Karyawan & Daus & \\
\hline (A) Kepribadian & (A2) Sopan & $\checkmark$ \\
\hline (B) Taat Aturan & (B2) Kurang Patuh & $\checkmark$ \\
\hline (C) Kedisiplinan & (C2) Disiplin & $\checkmark$ \\
\hline (D) Tanggung Jawab & (D1) Sangat Besar & 2 \\
\hline (E) Ketelitian & (E2) Teliti & $\checkmark$ \\
\hline (F) Produktivitas & (F2) Sedikit & $\checkmark$ \\
\hline (G) Kerapian & (G1) Sangat Rapi & $\checkmark$ \\
\hline Proses dengan Bayes & sififer & \\
\hline
\end{tabular}

Gambar 5. Halaman Proses Bayesian Classifier

4. Halaman Hasil Proses

Hasil proses dengan bayesian classifier akan ditampilkan pada halaman ini seperti ditunjukkan Gambar 6.

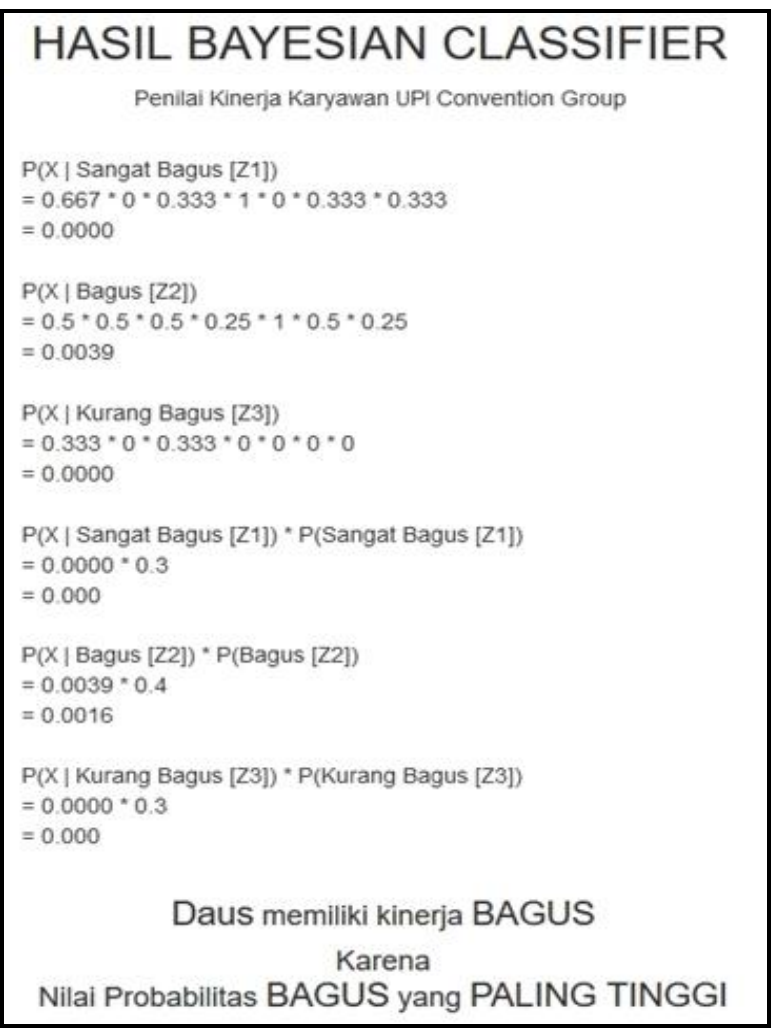

\section{Gambar 6. Halaman Hasil Proses}

Halaman hasil proses memberikan kesimpulan berupa keputusan dari kriteria yang dimasukkan sebelumnya. Dari data karyawan bernama Daus dengan nilai input yang dimasukkan sebagai data testing, dapat dilihat hasilnya bahwa Daus memiliki kinerja Bagus. 


\section{KESIMPULAN}

Kesimpulan yang bisa diperoleh dari penelitian ini adalah metode Bayesian Classifier yang digunakan sangat membantu manajer operasional UPI Convention Group untuk melakukan penilai kinerja karyawan dan aplikasi data mining yang diimplementasikan sangat mudah digunakan oleh manajer operasional.

Kriteria yang digunakan yaitu kepribadian, taat aturan, kedisiplinan, tanggung jawab, ketelitian, produktivitas dan kerapian sangat cocok digunakan untuk penilaian kinerja karyawan di UPI Convention Group.

\section{SARAN}

Penelitian ini masih terdapat kekurangan, sehingga perlu penyempurnaan kedepannya. Maka saran yang bisa diberikan adalah perlu dilakukan penelitian lanjutan dari penelitian ini untuk bisa mencakup semua aspek dari karyawan, sehingga akan sangat memudahkan pimpinan dalam mengatur karyawan. Hendaknya perlu dikaji lagi metode yang lebih tepat dan cocok untuk digunakan dalam penilaian kinerja karyawan agar hasil yang diperoleh lebih akurat.

\section{DAFTAR PUSTAKA}

Han, J. and Kamber, M., 2011, Data Mining Concepts and Techniques Third Edition. Elsevier

Mandala, E.P.W., 2015. Web Programming Project 1 : epwm Forum. Yogyakarta : Penerbit Andi

Mandala, E.P.W., 2015., Data Mining Menggunakan Bayesian Classifier Untuk Menentukan Kelayakan Kendaraan Yang Akan Dijual Pada Showroom Motor Bekas. Prosiding Senatkom, 1, pp 42-49

Mulyati, S and Setiani, N., 2018, Identifying Students' Academic Achievement And Personality Types With Naive Bayes Classification. Sebatik, 22(2), pp 64-68

Palupi, S., Lailiyah, S and Sihotang, V., 2018., Sistem Pendukung Keputusan Pemerimaan Karyawan Pada
PT. Suryaintan Tri Lestari Dengan Metode Ahp Berbasis Web., Sebatik, 11(1), pp 25-31

Pauziah, U., 2017., Analisis Penentuan Karyawan Terbaik Menggunakan Metode Algoritma Naive Bayes (Studi Kasus PT. XYZ), Prosiding Diskusi Panel Pendidikan, pp 94-102

Putri, D.E., 2015, Metode Non Hierarchy Algoritma KMeans Dalam Mengelompokkan Tingkat Kelarisan Barang (Studi Kasus : Koperasi Keluarga Besar Semen Padang). Prosiding Senatkom, 1, pp 36-41

Ramadhoni, S., Mandala, E.P.W and Afdhal, M., 2019, Sistem Pakar Diagnosa Penyakit Kulit Pada Anjing Menggunakan Metode Bayes, Seminar Nasional Teknologi Komputer \& Sains (SAINTEKS), 1 (1), pp $873-876$

Ridwan, M., 2017, Analisis Pengaruh Kompensasi, Disiplin Kerja Dan Komitmen Terhadap Kinerja Karyawan Pada UPI Convention Center Padang, Ekobistek, 6(1), pp 178-185

Saefudin and Lestari, S., 2015, Sistem Pendukung Keputusan Untuk Penilaian Kinerja Karyawan PT. Mulya Spindo Mills Menggunakan Metode Algoritma C4.5. Jurnal Protekinfo, 2, pp 40-43

Sari, D.P., Rinawati, D.I., Arvianto, A. and Mujur, M., 2014., Perancangan Sistem Penilaian Kinerja Karyawan Dan Pemberian Reward Menggunakan Analytical Hierarchy Process (AHP) Dan Fuzzy Synthetic Decision Approach, J@TI Undip, IX(3), pp 181-186

Windarto, A.P., 2017, Penilaian Prestasi Kerja Karyawan Ptpn Iii Pematangsiantar Dengan Metode Simple Additive Weighting (SAW), Jurnal Riset Sistem Informasi Dan Teknik Informatika (JURASIK), 2(1), pp 84-95

Witten, I.H., Eibe, F. and Hall, M.A., 2011, Data mining Practical Machine Learning Tools and Techniques 3rd Edition, Elsevier 